University of Nebraska - Lincoln

DigitalCommons@University of Nebraska - Lincoln

2006

\title{
Trend Identification in Twentieth-Century U.S. Snowfall: The Challenges
}

\author{
Kenneth E. Kunkel \\ Illinois State Water Survey, Illinois Department of Natural Resources, kkunkel@uiuc.edu \\ Michael A. Palecki \\ Illinois State Water Survey, Illinois Department of Natural Resources \\ Kenneth G. Hubbard \\ University of Nebraska - Lincoln, khubbard1@unl.edu \\ David A. Robinson \\ The State University of New Jersey, New Brunswick \\ Kelly T. Redmond \\ Desert Research Institute, Reno
}

See next page for additional authors

Follow this and additional works at: https://digitalcommons.unl.edu/natrespapers

Part of the Natural Resources and Conservation Commons, Natural Resources Management and Policy Commons, and the Other Environmental Sciences Commons

Kunkel, Kenneth E.; Palecki, Michael A.; Hubbard, Kenneth G.; Robinson, David A.; Redmond, Kelly T.; and Easterling, David R., "Trend Identification in Twentieth-Century U.S. Snowfall: The Challenges" (2006). Papers in Natural Resources. 1241.

https://digitalcommons.unl.edu/natrespapers/1241

This Article is brought to you for free and open access by the Natural Resources, School of at DigitalCommons@University of Nebraska - Lincoln. It has been accepted for inclusion in Papers in Natural Resources by an authorized administrator of DigitalCommons@University of Nebraska - Lincoln. 
Authors

Kenneth E. Kunkel, Michael A. Palecki, Kenneth G. Hubbard, David A. Robinson, Kelly T. Redmond, and David R. Easterling 


\title{
Trend Identification in Twentieth-Century U.S. Snowfall: The Challenges
}

\author{
Kenneth E. Kunkel And Michael A. Palecki \\ Illinois State Water Survey, Illinois Department of Natural Resources, Champaign, Illinois \\ KenNeth G. HubBard \\ University of Nebraska at Lincoln, Lincoln, Nebraska \\ DAvid A. Robinson \\ Rutgers, The State University of New Jersey, New Brunswick, New Jersey \\ KeLly T. REDMOND \\ Desert Research Institute, Reno, Nevada \\ DAVID R. EASTERLING \\ National Climatic Data Center, Asheville, North Carolina
}

(Manuscript received 20 March 2006, in final form 18 October 2006)

\begin{abstract}
There is an increasing interest in examining long-term trends in measures of snow climatology. An examination of the U.S. daily snowfall records for 1900-2004 revealed numerous apparent inconsistencies. For example, long-term snowfall trends among neighboring lake-effect stations differ greatly from insignificant to $+100 \%$ century $^{-1}$. Internal inconsistencies in the snow records, such as a lack of upward trends in maximum seasonal snow depth at stations with large upward trends in snowfall, point to inhomogeneities. Nationwide, the frequency of daily observations with a 10:1 snowfall-to-liquid-equivalent ratio declined from $30 \%$ in the 1930 s to a current value of around $10 \%$, a change that is clearly due to observational practice. There then must be biases in cold-season liquid-equivalent precipitation, or snowfall, or both. An empirical adjustment of snow-event, liquid-equivalent precipitation indicates that the potential biases can be statistically significant.

Examples from this study show that there are nonclimatic issues that complicate the identification of and significantly change the trends in snow variables. Thus, great care should be taken in interpretation of time series of snow-related variables from the Cooperative Observer Program (COOP) network. Furthermore, full documentation of optional practices should be required of network observers so that future users of these data can properly account for such practices.
\end{abstract}

\section{Introduction}

Snow plays a critical role in the climate system through its effect on surface albedo and emissivity. It is likely to be a sensitive indicator of climate change in the cold season. Temporal variability in snow properties reflects fluctuations in both precipitation and tempera-

Corresponding author address: Dr. Kenneth E. Kunkel, Illinois State Water Survey, 2204 Griffith Dr., Champaign, IL 61820-7495. E-mail:kkunkel@uiuc.edu

DOI: $10.1175 / J T E C H 2017.1$

(C) 2007 American Meteorological Society ture, sometimes with great sensitivity, and thus can add interpretive information about those elements. Snow on the ground and snowfall have a variety of significant socioeconomic positive and negative effects. Snow is an important component of annual runoff, recharge, and water supplies, and greatly affects water management in the northern and western United States. Rapid melt of snowpack is a major cause of floods in the northern United States. Recent studies have examined historical variability in snow cover (Hughes and Robinson 1996; Frei et al. 1999). However, studies of trends in other aspects of snow climatology, such as snowfall and snow 
depth, have generally examined records from the latter half of the twentieth century because digital data prior to that point has heretofore been sparse. Burnett et al. (2003) studied snowfall trends at several stations in the lake-effect snowbelts in the Great Lakes basin and found upward trends since 1951. Norton and Bolsenga (1993) identified an upward trend in lake-effect snowfall for the period of 1951-80. Groisman et al. (2004) found a decreasing trend in spring season snowfall and a general shortening of the snow season, and stated that this was likely associated with recent spring season warming. A variety of recent studies pointed to significant and potentially serious declines in spring snowpack in the western United States (Mote 2003; Mote et al. 2005; Hamlet et al. 2005; Regonda et al. 2005; Stewart et al. 2005), and a trend toward more precipitation falling as rain than snow (Knowles et al. 2006).

During the first half of the twentieth century, there were significant climate trends and fluctuations that may have affected and/or been affected by the snowfall climatology. Most notably, there was substantial warming during the first 40 or so years of the century. Studies of snow (amount of fall and depth) variability and trends should provide further insights into the changes that occurred during that period.

For the past several years, the U.S. Congress has funded the Climate Data Modernization Program (CDMP), which has largely focused on digitizing climate data archived on hard copy forms and microfilm images (see information online at http://www.ncdc. noaa.gov/oa/climate/cdmp/cdmp.html). One of the most important achievements of the CDMP was the completion of the keying of Cooperative Observer Program (COOP) network daily data for the period of 1892-1948. These new COOP daily data have greatly increased the spatial density of digital data for the 1892-1948 period across the United States, and have provided interesting documentation of extreme temperature and precipitation event frequency variations for the conterminous United States (Kunkel et al. 2003, 2004).

An initial examination of trends in snowfall using this newly expanded COOP dataset revealed inconsistencies that complicate interpretation of the results. The purpose of this paper is to document certain aspects of the snow data that must be considered in any analysis. The issues identified here are consequential, but it is not yet clear whether the problems are tractable. Section 2 ("Data and methods") describes the datasets and analysis procedures. Section 3 ("Results") discusses snowfall trends for 1900-2004, shows an example of inconsistent temporal characteristics among neighboring lake-effect stations, and describes potential sources of inhomogeneities in snowfall time series. The use of the 10:1 snowfall-to-water-equivalent ratio is discussed to illustrate that there are ramifications for long-term trend assessment. Section 4 ("Conclusions") provides a concise summary of conclusions.

\section{Data and methods}

The snowfall (depth of snow that accumulated since the previous observation) and snow depth (total depth of snow on ground) data were combined from two datasets, all derived from observations taken by the U.S. COOP. These were the routinely digitized COOP data, denoted as DSI-3200 by the National Climatic Data Center (NCDC), and the newly digitized pre-1948 COOP data produced by CDMP, denoted as DSI-3206 (Kunkel et al. 2005). The period (1930-2000) was used to identify the station set used in this study. This set consisted of 1119 stations with less than $10 \%$ missing snowfall data for the 1930-2000 period and an annual average snowfall total $>12.5 \mathrm{~cm}$ (Fig. 1a). A subset of stations with less than $10 \%$ missing snowfall data for the period of 1900-2000 was also identified (Fig. 1b) for analyses extending back to the beginning of the twentieth century. For certain analyses, the stations were categorized by mean annual snowfall into three groups for the ranges of 12.5-50 ("low"), 50-200 ("moderate"), and $>200$ ("high") $\mathrm{cm}$ (Fig. 1).

Annual total snowfall, annual maximum snow depth, and precipitation reported on days with snowfall were computed for each station for each year (1 July-30 June) with less than $20 \%$ missing data (both snowfall and precipitation) during 1 October-31 May. For national average time series, annual station values of snowfall $s(y)$ for year $y$ were first converted to annual anomalies $A(y)$ defined as

$$
A(y)=s(y)-\frac{1}{\sum_{y=1971}^{2000} F(y)} \sum_{y=1971}^{2000} F(y) \times s(y),
$$

where $F(y)$ is a flag equal to 1 if there are data for year $y$ and equal to 0 if data are missing, and the mean is calculated for the period of 1971-2000. Then, annual standardized anomalies $N(y)$ were calculated by

$$
N(y)=\frac{A(y)}{\sigma},
$$

where $\sigma$ is the standard deviation of $s(y)$, also calculated for 1971-2000. For the time series analysis presented in Fig. 2, the standardized anomalies were arithmetically averaged for all stations in a climate division. Finally, national values were obtained by areally 
a)1930-2004 stations

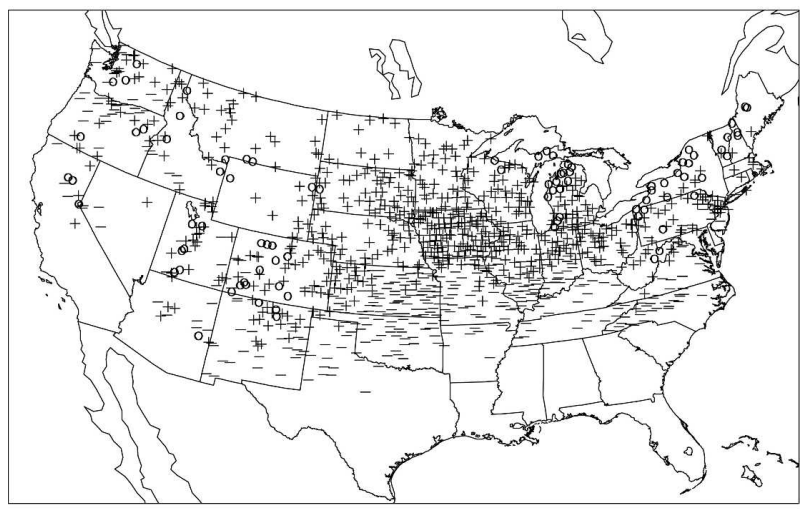

b) 1900-2004 stations

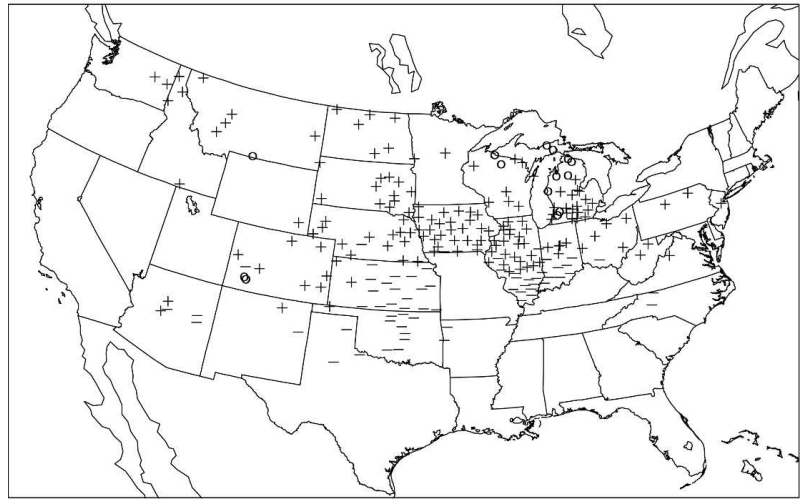

FIG. 1. Locations of stations with less than $10 \%$ missing data for (a) 1930-2004 and (b) 1900-2004. The symbol denotes mean annual snowfall for categories of 12.5-50 (“-"), 50-200 (“+”), and $>200$ ("o") cm.

weighting the divisional averages. This area weighting was applied because of the uneven spatial density of stations (Fig. 1) and avoids overweighting the highdensity central United States in the national composite time series of Fig. 2.

\section{Results}

Time series of U.S. annual snowfall standardized anomalies were calculated for 1930-2004 using the full complement of 1119 stations and for 1900-2004 using a subset of 233 stations with less than $10 \%$ missing data for 1900-2000. Separate time series were calculated for low-, moderate-, and high-snowfall stations. These time series (Fig. 2) exhibit substantial interannual variability. For the 233-station subset, the spatial coverage is less than ideal, with substantial areas unsampled, particularly in the western United States, increasing the uncertainty of the estimates in the early part of the time series. This is especially true for the small number of a) 1930-2000 long-term station set

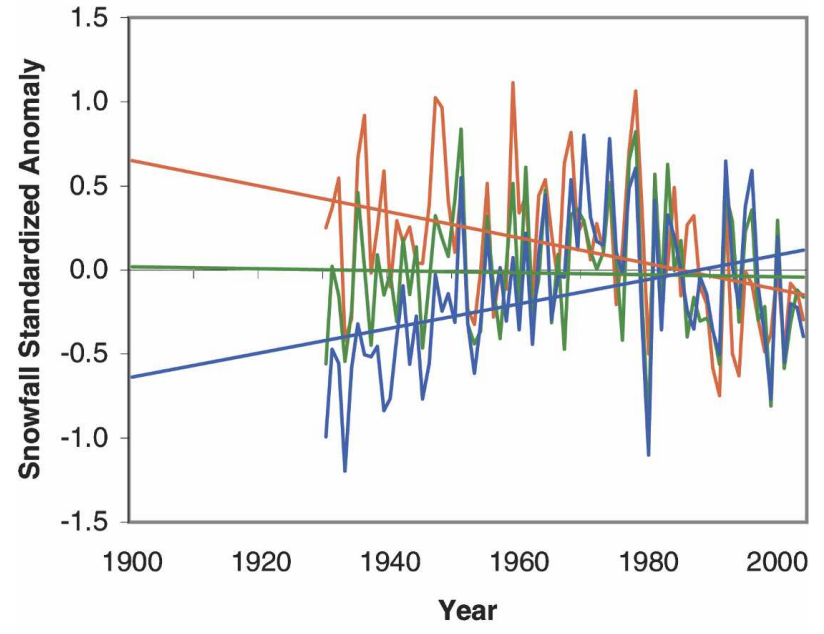

b) 1900-2000 long-term station set

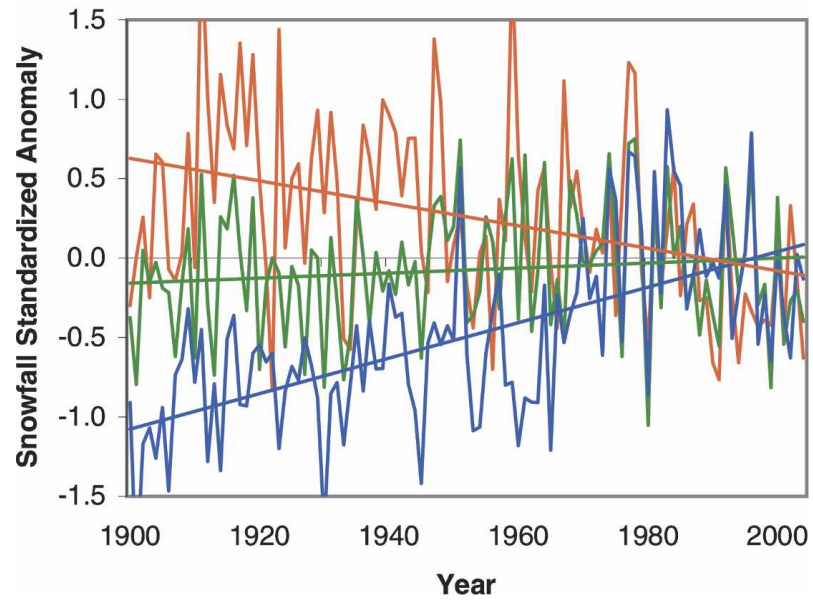

FIG. 2. U.S. averaged time series of snowfall (expressed as standardized anomalies) for long-term stations from Figs. 1a and 1b. Separate time series are shown for stations with mean annual snowfall of 12.5-50 (red), 50-200 (green), and >200 (blue) $\mathrm{cm}$. Straight lines show trends as determined by least squares fits to the time series.

high-snowfall category stations, which are predominantly concentrated around the Great Lakes (Fig. 1b). During the overlapping period of 1930-2004, variations are generally similar between the two time series, although the variations are larger for the 233-station set, which is a reflection of the greater uncertainty. A key feature of these time series is the substantial differences among the mean annual snowfall categories. For both 1930-2004 (Fig. 2a) and 1900-2004 (Fig. 2b), the trend is upward for high-, flat for moderate-, and downward for low-snowfall stations. The trends are statistically significant at the $95 \%$ level of confidence for high- and low-snowfall stations for both periods (Table 1). The downward trend for low-snowfall stations could reflect 
TABLE 1. Snowfall trends (standardized anomalies per decade) for time series in Fig. 1 for 1930-2004 and 1900-2004. The trends are based on all stations with $<10 \%$ missing data for the trend period. The number of available stations is shown in parentheses. An asterisk indicates a statistically significant trend at the $95 \%$ level of confidence.

\begin{tabular}{ccc}
\hline \hline Mean annual snowfall & $1930-2004$ trend & $1900-2004$ trend \\
\hline $12.5-50 \mathrm{~cm}$ & $-0.077(358)^{*}$ & $-0.071(65)^{*}$ \\
$50-200 \mathrm{~cm}$ & $-0.006(639)$ & $+0.016(154)$ \\
$>200 \mathrm{~cm}$ & $+0.072(87)^{*}$ & $+0.112(14)^{*}$ \\
\hline
\end{tabular}

the decreasing southward extent of snowfall events and could be interpreted as a response to anthropogenically forced changes in the climate system. Even the moderate- and high-snowfall stations, while not exhibiting a long-term downward trend, show lower snowfall values during 1990-2004 than in the previous two 15-yr periods (Table 2). However, as will be shown, a number of inconsistencies are present in the dataset and this simple interpretation of these time series must be tempered by uncertainties arising from the inconsistencies. Another feature of the time series is the substantial interannual variability (Table 2). Using the standard deviation over 15-yr blocks as a measure (Table 2), the interannaual variability is quite high in comparison with the variability of 15 -yr block means.

Doesken and Judson (1997) provided examples of inhomogeneities in individual station snow time series caused by a number of factors, including changes in observer, location, and observational practices. Although inhomogeneities are present in all large climate datasets, the interpretation of time series, such as in Fig. 2 , generally assumes that the timing and sign of any biases in individual stations are random, such that the net effect is negligible when averaging a large number of stations. Thus, of central importance is the identification of any inhomogeneities that are not random.

\section{a. Lake-effect snowbelt example}

An example from the lake-effect snowbelts of the western Great Lakes illustrates some of the issues in the examination of snow data. Time series of annual snowfall at four stations (three of which are located within $100 \mathrm{~km}$ of each other, and the fourth, Spooner, Wisconsin, is about $150 \mathrm{~km}$ west of Minoqua Dam) extending back to the early part of the twentieth century (Fig. 3) exhibit large trend differences. At both Ironwood, Michigan, and Minocqua Dam, Wisconsin, within the snowbelt influence of Lake Superior, there are large upward trends highlighted by a jump in the 1960s. In contrast, there is very little trend at Spooner and Stambaugh, Michigan. Spooner is not located in the
TABLE 2. The 15-yr mean and standard deviation (in parentheses) of snowfall standardized anomalies for three snowfall categories.

\begin{tabular}{llrc}
\hline & $12.5-50 \mathrm{~cm}$ & $50-200 \mathrm{~cm}$ & $>200 \mathrm{~cm}$ \\
\hline $1900-14$ & $+0.40(0.64)$ & $-0.21(0.38)$ & $-1.01(0.42)$ \\
$1915-29$ & $+0.57(0.60)$ & $-0.11(0.36)$ & $-0.71(0.21)$ \\
$1930-44$ & $+0.23(0.64)$ & $-0.11(0.38)$ & $-0.57(0.28)$ \\
$1945-59$ & $+0.27(0.68)$ & $+0.04(0.40)$ & $-0.20(0.33)$ \\
$1960-74$ & $+0.31(0.39)$ & $+0.10(0.33)$ & $+0.16(0.38)$ \\
$1975-89$ & $+0.16(0.52)$ & $0.00(0.49)$ & $-0.02(0.43)$ \\
$1990-2004$ & $-0.28(0.37)$ & $-0.14(0.38)$ & $-0.13(0.42)$ \\
\hline
\end{tabular}

lake-effect snowbelt and there could be changes in snowfall within, but not outside of, the lake-effect snowbelts, as has been found by Burnett et al. (2003). However, Stambaugh is also located within the Lake Superior snowbelt, which is only about $100 \mathrm{~km}$ east of Minocqua Dam and is at a similar distance from Lake Superior as from Minocqua Dam. Although large spatial differences are common in individual lake-effect events, such sizeable differences in multidecadal trends among the lake-effect-influenced stations were not expected. The implication is that there was an abrupt and

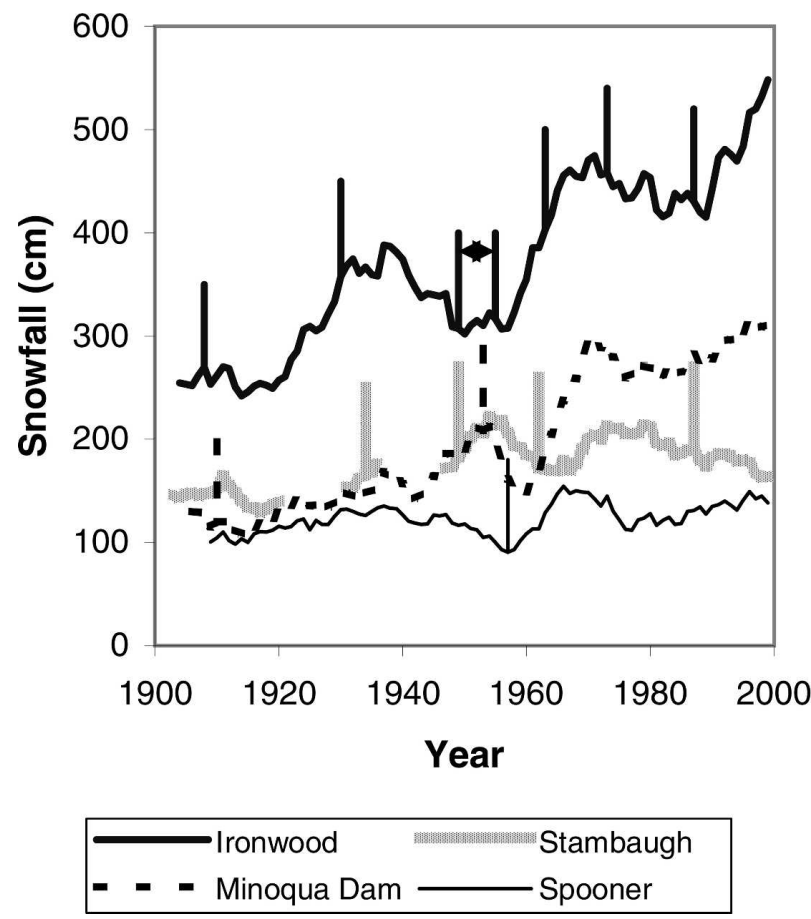

FIG. 3. Time series of annual snowfall at four nearby stations located within or near the Lake Superior snowbelt. The time series have been smoothed with 11-yr moving average filter. The vertical lines indicate the times of station moves. The horizontal arrow on the Ironwood time series indicates a period when a series of moves occurred with only the first and last moves shown by vertical lines. 


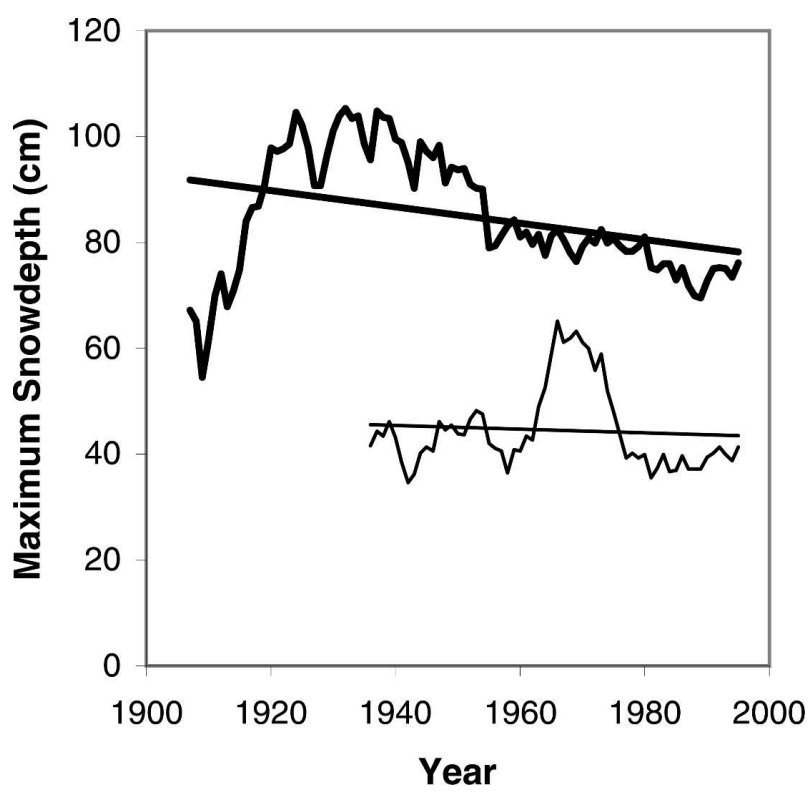

FIG. 4. Time series of annual maximum snow depth at Ironwood (thick line) and Spooner (thin line). The time series have been smoothed with 11-yr moving average filter. Straight lines show trends as determined by least squares fits to the time series.

permanent shift in atmospheric processes affecting lake-effect snow events that influenced some stations but not others, a possibility that seems unlikely (although this cannot be discounted with complete certainty). Instead, the differences probably reflect inhomogeneities in the snowfall records. The individual station records are also not necessarily internally consistent. The time series (Fig. 4) of seasonal maximum snow depth for Ironwood and Spooner (the snowdepth data for Stambaugh and Minocqua Dam were too incomplete to analyze) indicates little trend at Spooner, which is apparently consistent with the lack of trend there in the snowfall time series. At Ironwood, the maximum snow-depth values are found in the early half of the record, with a slight decreasing trend since the 1940s. This is seemingly inconsistent with the large upward trend in snowfall. One can imagine physical reasons for this inconsistency. Perhaps the average snowfall density has become smaller in recent years so that greater compaction occurs. Or, perhaps there are more frequent/severe melting episodes during the snow season, decreasing the maximum snowpack depth experienced for a given amount of snowfall. If these or other physical changes have occurred, this would be of great interest in itself, reflecting subtle but profound changes in the climate. Both of the above reasons would likely be associated with changes in temperature; however, a time series of winter season temperature (not shown) does not indicate any temporal changes correlating with the timing of the apparent inconsistencies.

One could also ascribe some of the inconsistencies in trends to known station changes and relocations (shown in Fig. 3). Such moves could change the exposure (and thus microclimate) of the observing site; any resulting changes in wind, temperature, radiation, etc., could affect the accumulation, drifting, and melting of snow. For example, the Ironwood COOP station moved several times during the 1950s in and around the municipal boundaries (the arrows in Fig. 3 indicate the first and last moves of this set), but the station began and ended the decade at approximately $1520-\mathrm{ft}$ elevation, at a location run by the Lake Superior Power District Company. An incomplete metadata entry indicated a station change occurred in 1963 (around the time of increase in snowfall), but there are no specifics given, and the climatological data publications during the period indicate that the same observer of record (power company), elevation, latitude, and longitude continued during the 1960s. In July 1973, metadata records indicate a station move of approximately 1.5 miles to the northwest, toward Lake Superior, to a new site at 1430 -ft elevation run by the Wastewater Treatment Plant. There is some confusion, though, because a relocation notation in the new MI3 online metadata system at the National Climatic Data Center states that the move in July 1973 was $200 \mathrm{ft}$ to the southeast of its original position, when the latitude and longitude change would indicate the further distance referenced above. Therefore, there might have been an additional undocumented change prior to July 1973. The metadata records at the other three stations do not provide any resolution of the inconsistencies (Fig. 3). At Minocqua Dam, there is no record of a station move around the time of rapid snowfall increase. Several station moves are recorded at Stambaugh, but there are no obvious snowfall shifts associated with these moves. The single station move at Spooner does not appear to result in a permanent shift in snowfall.

An examination of the Minocqua Dam record in comparison to that of Ironwood and 13 other long-term stations closest to Minocqua Dam (ranging in distance from 26 to $195 \mathrm{~km}$ away) indicates that an undocumented station move or procedural change may have occurred in the mid-1960s at both locations. In this analysis, the Minocqua Dam anomalies $A(y)$ were subtracted from each neighboring station's values of $A(y)$. The annual anomaly differences between Minocqua Dam and the 13 nearby stations indicate a coherent shift between the cluster of stations having anomalies 50-100 cm more positive than Minocqua Dam prior to 1967 to having anomalies $50-100 \mathrm{~cm}$ more negative af- 


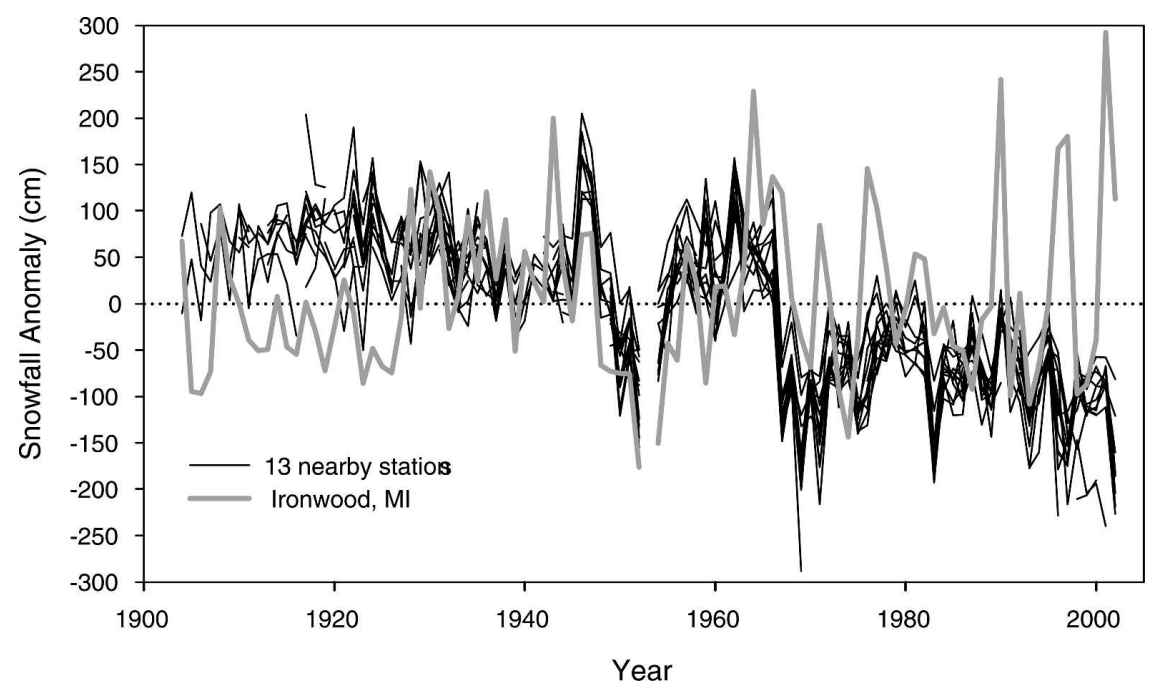

FIG. 5. Time series of station annual snowfall anomalies minus annual snowfall anomalies at Minocqua Dam. Thin solid lines show time series for Big St. Germain Dam, Hancock Experimental Farm, Long Lake Dam, Marshfield, Mather 3 NW, Medford 1 SW, Merrill, Neillsville 3 SW, Phelps Deerskin Dam, Prentice No. 2, Waupaca (all in Wisconsin), and Stambaugh. Thick gray line shows the time series for Ironwood.

terward, a net relative shift of 100-200 $\mathrm{cm}$ in just a few seasons (Fig. 5). In Fig. 5, the Minocqua Dam snowfall anomaly differences from Ironwood (gray line) were relatively small. The overall trend of these anomaly difference time series ranges from -16 to $-29 \mathrm{~cm}$ decade $^{-1}$ for the 13 stations (all statistically significant at the $95 \%$ level of confidence), while the trend for Minocqua Dam is a small and statistically insignificant at $+4 \mathrm{~cm}_{\text {decade }}{ }^{-1}$. Therefore, Minocqua Dam and Ironwood remained synchronized through the mid-1960s, and this could reflect a change in observational procedures that might be common to both stations. Nearby stations with similar distances to Lake Superior did not have this mid-1960s step change, so it is unlikely to be related to natural changes in lake-effect processes, in this case. This example indicates that statistical approaches to station inhomogeneity are needed to complement incomplete metadata records in determining station change-induced variations in long time series of climate observations.

\section{b. Sources of inhomogeneities}

Other changes that can affect snowfall records include observer instructions, adherence to instructions, time of observation, observer changes, and the use of snowboards. At present, observers have the option of taking measurements at 6-h intervals, clearing the snowboard after each measurement (http://www.nws. noaa.gov/om/coop/snowguid.htm). This practice is known to inflate snowfall totals relative to daily mea- surements. There is no indication in the published instructions that this was an option in the earlier part of the record through 1989 (U.S. Department of Commerce NOAA/National Weather Service 1989). Optional instructions such as this present a special problem because there is no documentation whether such an option was used. One can imagine that for the typical observer the measurement of snowfall at subdaily intervals, if practiced at all, might not be done all of the time, depending on the observer's schedule or circumstances during a particular event. The present instructions also indicate that the snowfall measurement should be taken as soon as possible after the end of an event, rather than waiting until the standard time of observation. Earlier instructions do not include this practice. Again, this would inflate snowfall totals relative to measurements at the time of observation by shortening the time available for compaction. Adherence to this modern instruction might also depend on the observer's schedule or circumstances during a particular event. For measurements taken at the standard time of observation, a change in observation time from late afternoon to early morning (the relative proportion of morning observers increased during the twentieth century) can induce an artificial increase in snowfall because snowfall events ending several hours before observation time will experience cooler temperatures and less frequent melting for morning observers than for afternoon observers. A change in observer not involving a station move can also introduce artificial 


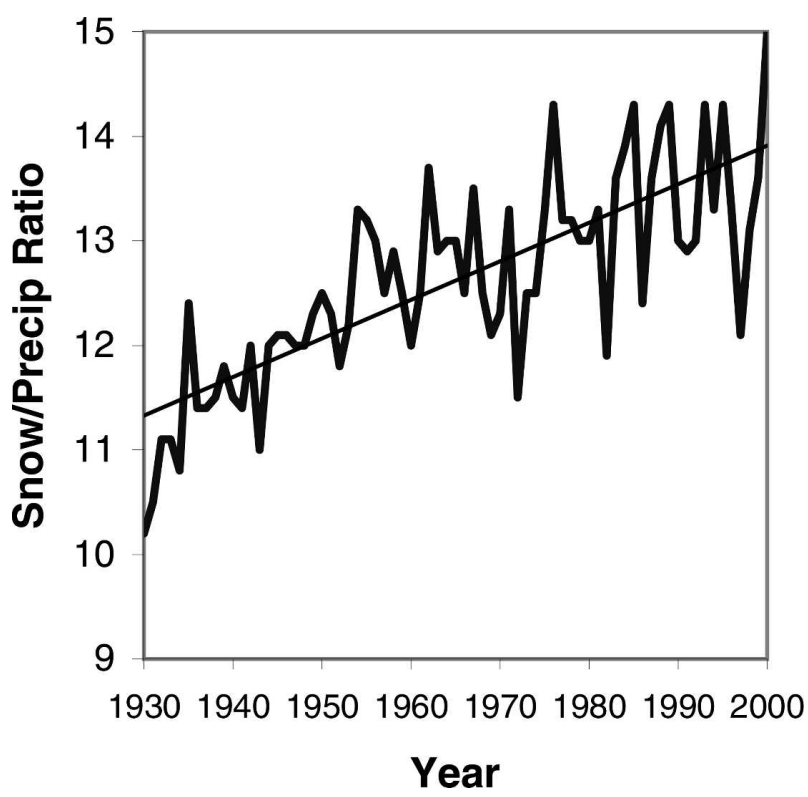

FIG. 6. Annual median value of snowfall-to-liquid-equivalent ratio for all long-term U.S. snowfall stations used in this study for all days with snowfall $>5 \mathrm{~cm}$. Straight line show trend as determined by least squares fit to the time series.

changes if the new observer makes different choices about where to make measurements after wind-blown events or whether to follow an optional practice such as subdaily measurements. The use of snowboards is not universal at the present time and early instructions do not mention their use, indicating that many or most long-term records will not reflect continuous use. The lack of a board most likely would lead to inflated snowfall totals if the observer measured over grass (first snow on the grass or the grass had been cleared), or reduced totals when snow previously was on the ground and the observer simply subtracted yesterday's snow depth from today's to get "snowfall." The importance of most of the above issues cannot be determined from documentation. As noted previously, an implicit assumption in analysis is that these effects are random and largely canceled when considering a large number of stations. However, some of these (e.g., the shift from mostly afternoon to mostly morning observers, the practice of subdaily measurements) may introduce biases that should not be ignored in trend analysis.

An example of a potentially important shift in observational practice is the use of "rules of thumb" for estimation. A time series of the annual median ratio of snowfall to reported liquid-equivalent precipitation is shown in Fig. 6; this annual median is derived from a single cumulative frequency distribution, which in turn is constructed from all daily ratio values for days with snowfall in excess of $5 \mathrm{~cm}$ during a year for the 1119

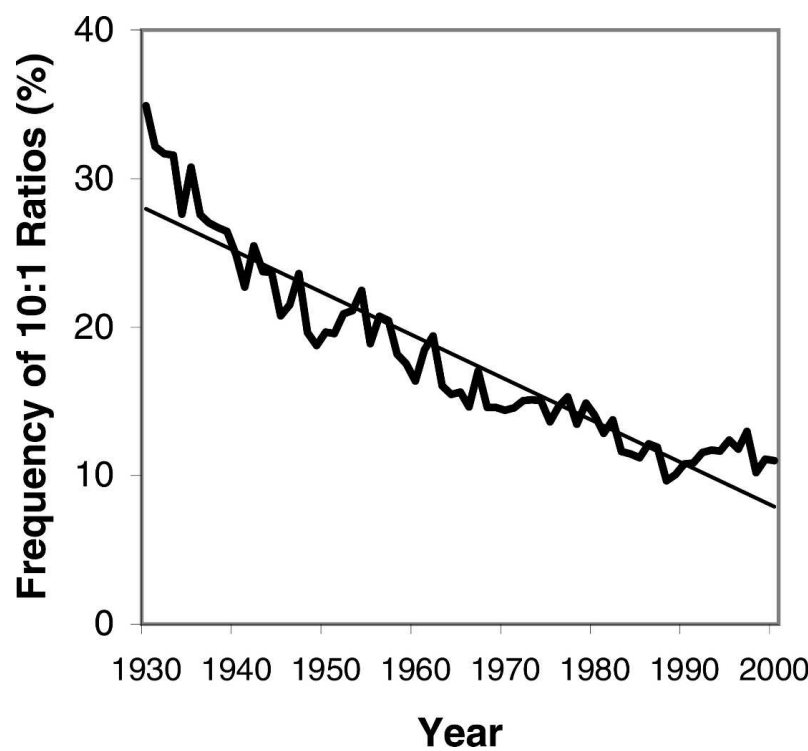

FIG. 7. Time series of the frequency of daily values of 10:1 for the snowfall-to-liquid-equivalent ratio based on all long-term U.S. snowfall stations. Straight line shows trend as determined by least squares fit to the time series.

long-term stations. The median ratio exhibits an increase from about 10 in the early part of the record to 13-14 in the 1990s. Baxter et al. (2005) developed a climatology of the snowfall to liquid-equivalent ratio using data for 1971-2000, finding an average value of 13 for the latter part of the twentieth century. An examination of some individual stations revealed that the early part of the record has a high number of days with a 10:1 ratio. A time series of the frequency of exactly 10:1 ratios, first computed for each long-term station and then averaged for all of the long-term stations (Fig. 7), shows a decrease from around $30 \%$ in the 1930 s to about $10 \%$ in the 1990s. Instructions to observers in the early to midtwentieth century provided as an option the measurement of snowfall and then estimation of liquid equivalent using a 10:1 ratio. In U.S. Department of Agriculture Weather Bureau (1899, p. 19), the following instruction is given: "Whenever it is impractical to melt the snow..., one-tenth of [the snowfall] will give an approximate value, in water, for the snow which could not be melted." Similar instructions appear in all subsequent publications through 1941 (U.S. Department of Agriculture Weather Bureau 1941). However, a later publication (U.S. Department of Commerce Weather Bureau 1952) no longer explicitly included this option. Although this was an option in the early part of the record, an interesting and somewhat surprising feature is that there are spatial differences in the apparent application of this practice. The differences in the frequency of 10:1 ratios between 1930-50 and 1980- 


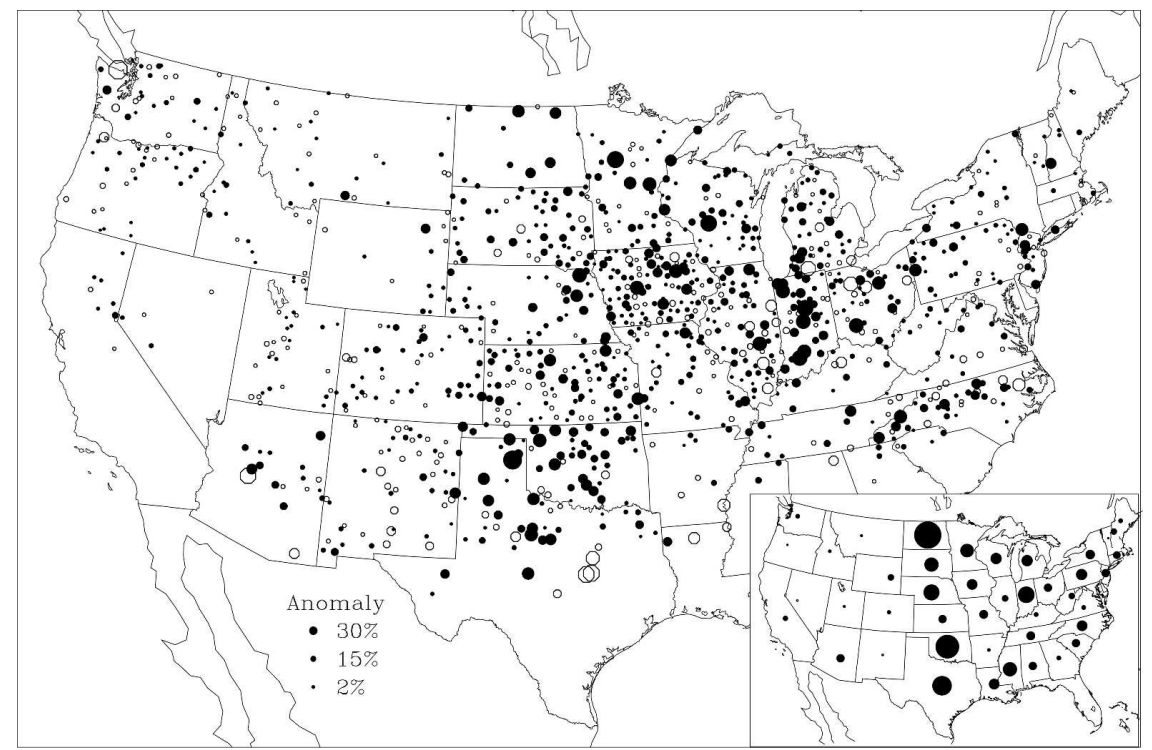

FIG. 8. Difference of the percent of snowfall-precipitation ratios equal to 10 between 1930-50 and 1980-2000 for each long-term snowfall station. Filled (open) circles indicate positive (negative) differences. The map inset shows state averaged values.

2000 were computed for each station and then averaged for each state (Fig. 8). In the central and eastern United States, there are many stations with large positive (filled-in circles) differences between these two periods (indicating higher frequencies in the $1930-50$ period), consistent with Fig. 7. Although there are some stations with the opposite behavior, the statewide averages are positive throughout the eastern United States. However, in the west, the differences are very small and the frequency of 10:1 ratios is relatively low in the early part of the record as well as the latter part. Thus, there appear to be periods of time in the past when operational approaches to snowfall and winter precipitation measurement differed by region, perhaps resulting from regional exposure issues such as susceptibility to undercatchment in the Great Plains. Instructions to observers, and implementation and adherence to guidance, could very well have varied between different administrative units, and any of these could have changed through time.

The instructions to observers (U.S. Department of Agriculture Weather Bureau 1941) state that it is the snowfall that is measured and the liquid equivalent that is estimated when both are not done simultaneously. This suggests that the snowfall records could be homogeneous (at least with respect to this practice), but coldseason liquid-equivalent precipitation in snowy climates could be problematic. An estimate of the potential magnitude of such an effect was explored by developing an adjusted precipitation time series. This was done for the 1900-2000 long-term stations (Fig. 1b), and for a subset consisting only of those stations in Fig. 1b with mean annual snowfall over $100 \mathrm{~cm}$. Daily snowfall and precipitation values with ratios different than 10:1 (and thus presumably reflecting the independent measurement of these two variables) were used to develop an empirically based categorical relationship between temperature and the snowfall:precipitation ratio. Simply, snowfall days were categorized by daily mean (average of maximum and minimum) temperature into bins of $2.8^{\circ} \mathrm{C}$ resolution. For all days in a category, the daily ratios were averaged. This was done separately for each station so that each station had a unique relationship. Note that this relationship is only an approximation because its calculation excludes all values with ratios exactly equal to $10: 1$, even though an unknown percentage of such values will be real. Then, for each day when the ratio was exactly $10: 1$, this relationship was used to calculate an adjusted precipitation value $P_{a}$ from the observed value $P$ as

$$
P_{a}=P[10 / R(T)]
$$

where $R(T)$ is the empirically determined ratio as a function of the daily mean temperature $T$.

A time series of observed and adjusted total precipitation from snowfall (Fig. 9) shows that the adjusted values are noticeably lower than the recorded precipitation early in the record (when the frequency of 10:1 ratio reports was high) for both sets of stations. The sizeable adjustments in the early part of the record have 
a) Mean annual snowfall $>12.5 \mathrm{~cm}$

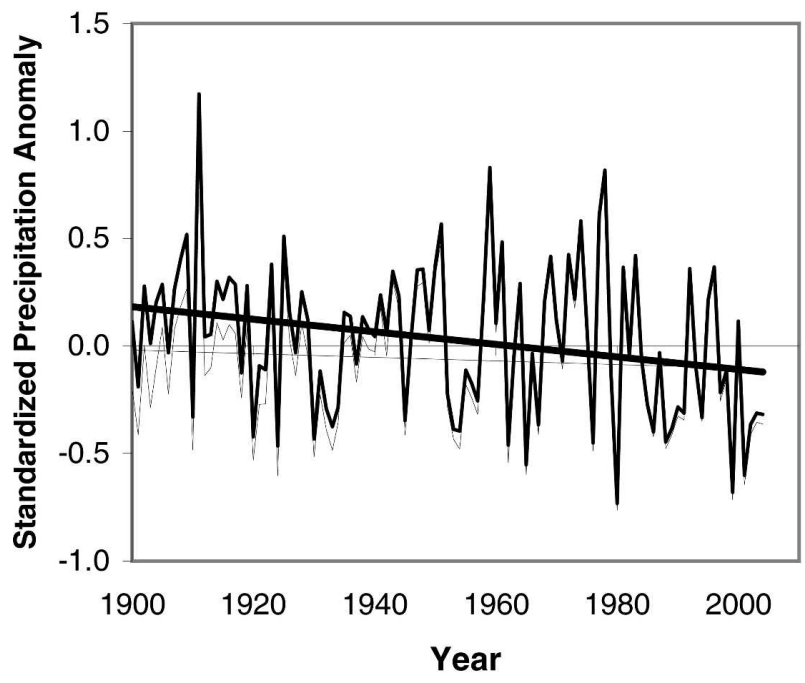

b) Mean annual snowfall $>100 \mathrm{~cm}$

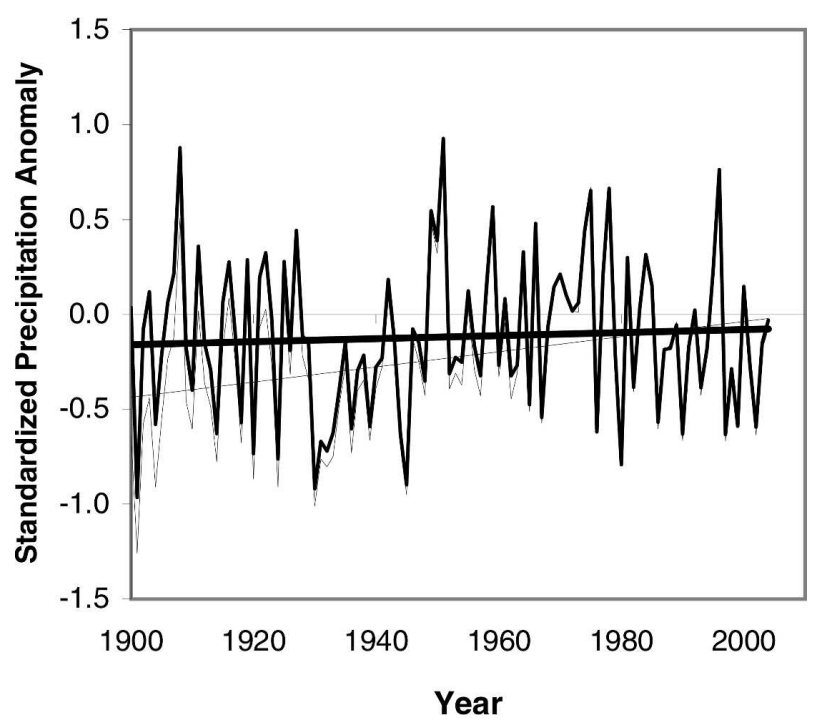

FIG. 9. Time series of precipitation from snowfall events averaged for (a) all stations shown in Fig. 1b and (b) all stations in Fig. $1 \mathrm{~b}$ with mean annual snowfall in excess of $100 \mathrm{~cm}$. Trend for observed (adjusted) values are shown by the solid (dashed) lines.

a substantial effect on the trend. In the case of the full station set (Fig. 9a), the trend for observed precipitation is downward and statistically significant at the $95 \%$ level of confidence, while the adjusted precipitation is not significantly different from zero. By contrast, for the snowier station set (Fig. 9b), the trend for observed precipitation is not significantly different from zero, while the trend for adjusted precipitation is upward and statistically significant at the $95 \%$ level of confidence. These trends are not necessarily a reflection of reality, but the differences in trends illustrate that observa- tional practice can have a nonnegligible impact on the results of trends analysis. Research involving snow liquid equivalent is ongoing; for example, Knowles et al. (2006) examined trends in the ratio of snow-liquidequivalent to total precipitation in the western United States primarily for the period after 1949. In that case, the focus on the latter half of the twentieth century and in the western United States where there are minimal trends in the frequency of 10:1 ratio observations (Fig. 8) minimizes the impact of this effect. However, studies examining the entire COOP period of record and for the entire United States will need to carefully consider the potential impacts of this nonclimatic effect.

\section{Conclusions}

The issues raised here indicate that care must be taken in interpreting temporal variations and trends in the COOP snow data and associated liquid-equivalent precipitation. In the early part of the record, the number of observers not making independent observations of snowfall and snowfall liquid equivalent was quite high, and was much higher than in the later part of the record. Observer instructions suggest that snowfall is likely the measured quantity and liquid equivalent is the estimated quantity, meaning that snowfall variations in the data may be real.

However, as our lake-effect snowbelt example shows, it is also clear that the snowfall time series are not homogeneous in some cases because of spatial variations on small scales that are highly unlikely to be real. Careful (and time consuming) inspection of the data and histories of individual stations appears to be necessary to identify quality snow stations suitable for trend analysis on a local scale.

On a larger scale, there is the possibility that the biases resulting from many types of station inhomogeneities may be random, and thus trends averaged over large areas may reflect reality. A notable exception is possible biases arising from the 10:1 snowfall-to-liquidequivalent-precipitation ratio rule of thumb. On average, the actual ratio is greater than 10 at most locations. Thus, application of this rule will result in an overestimate of the liquid equivalent. Because there is a decreasing trend in the frequency of 10:1 ratio reports, there must be either negative biases in winter precipitation trends or positive biases in snowfall trends, or even biases in both. Indeed, assuming that the biases occur in winter precipitation, an empirical adjustment of long-term time series of precipitation from snowfall for snowy locations makes a substantial change in the long-term trend. This is a particular concern for studies of snow liquid equivalent in the central and eastern 
United States covering the entire twentieth century, but may be of lesser importance for the western United States (e.g., Knowles et al. 2006) where there is little trend in the frequency of 10:1 ratio reports. These results suggest that (at least) two steps should be taken in the analysis of snow data. First, it is obvious that some stations are simply not suitable for use in trends analysis because of gross inhomogeneities. However, careful assessment of station histories and comparison with surrounding stations is required to identify which stations are in fact unsuitable. The authors are currently undertaking an assessment of all of the long-term stations (Fig. 1a) used in this analysis for this purpose. Second, some challenges may not be completely tractable because of lack of necessary information, for example, the specific practices (and time variations thereof) of a particular observer. In such cases, it seems that trends analyses should attempt to quantify the possible range and thereby provide insights into the uncertainties. The case study of snowfall water equivalent (Fig. 9) is an example where the results indicate the likely range of possible trends. The lack sufficient documentation about optional practices, and the consequences for long-term studies of climate variability and change, strongly suggest that cooperative observer instructions should be changed to require full documentation of optional practices.

Acknowledgments. This work was partially supported by National Oceanic and Atmospheric Administration Office of Global Program Awards NA05OAR4310016 and NA16GP1498. Additional support was provided by NOAA Cooperative Agreement NA17RJ1222. Any opinions, findings, and conclusions are those of the authors and do not necessarily reflect the views of NOAA or the institutions for which they work.

\section{REFERENCES}

Baxter, M. A., C. E. Graves, and J. T. Moore, 2005: A climatology of snow-to-liquid ratio for the contiguous United States. Wea. Forecasting, 20, 729-744.

Burnett, A. W., M. E. Kirby, H. T. Mullins, and W. P. Patterson, 2003: Increasing Great Lake-effect snowfall during the twentieth century: A regional response to global warming? J. Climate, 16, 3535-3541.

Doesken, N. J., and A. Judson, 1997: The Snow Booklet: A Guide to the Science, Climatology, and Measurement of Snow in the
United States. Colorado Climate Center, Colorado State University, 86 pp.

Frei, A., D. A. Robinson, and M. G. Hughes, 1999: North American snow extent: 1900-1994. Int. J. Climatol., 19, 1517-1534.

Groisman, P. Ya, R. W. Knight, T. R. Karl, D. R. Easterling, B. Sun, and J. H. Lawrimore, 2004: Contemporary changes of the hydrological cycle over the contiguous United States: Trends derived from in situ observations. J. Hydrometeor., 5, 64-85.

Hamlet, A. F., P. W. Mote, M. P. Clark, and D. P. Lettenmeier, 2005: Effects of temperature and precipitation trends on snowpack in the western U.S. J. Climate, 18, 4545-4561.

Hughes, M. G., and D. A. Robinson, 1996: Historical snow cover variability in the Great Plains region of the USA: 1910 through to 1993. Int. J. Climatol., 16, 1005-1018.

Knowles, N., M. D. Dettinger, and D. R. Cayan, 2006: Trends in snowfall versus rainfall in the western United States. J. Climate, 19, 4545-4559.

Kunkel, K. E., D. R. Easterling, K. Redmond, and K. Hubbard, 2003: Temporal variations of extreme precipitation events in the United States: 1895-2000. Geophys. Res. Lett., 30, 1900, doi:10.1029/2003GL018052.

,,-- K. Hubbard, and K. Redmond, 2004: Temporal variations in frost-free season in the United States, 1895-2000. Geophys. Res. Lett., 31, L03201, doi:10.1029/2003GL018624.

,,,---- K. K. Andsager, M. Kruk, and M. Spinar, 2005: Quality control of pre-1948 cooperative observer network data. J. Atmos. Oceanic Technol., 22, 1691-1705.

Mote, P. W., 2003: Trends in snow water equivalent in the Pacific Northwest and their climatic causes. Geophys. Res. Lett., 30, 1601, doi:10.1029/2003GL017258.

—, A. F. Hamlet, M. P. Clark, and D. P. Lettenmaier, 2005: Declining mountain snowpack in western North America. Bull. Amer. Meteor. Soc., 86, 39-49.

Norton, D. C., and S. J. Bolsenga, 1993: Spatiotemporal trends in lake effect and continental snowfall in the Laurentian Great Lakes, 1951-1980. J. Climate, 6, 1943-1956.

Regonda, S. K., B. Rajagapalan, M. Clark, and J. Pitlick, 2005: Seasonal cycle shifts in hydroclimatology over the western U.S. J. Climate, 18, 372-384.

Stewart, I. T., D. R. Cayan, and M. D. Dettinger, 2005: Changes towards earlier streamflow timing across western North America. J. Climate, 18, 1136-1155.

U.S. Department of Agriculture Weather Bureau, 1899: Instructions for voluntary observers. Weather Bureau No. 184, 23 pp.

_ 1941: Instructions for cooperative observers. 9th ed. Circulars B and C, Instrument Division, Weather Bureau No. 843, $34 \mathrm{pp}$.

U.S. Department of Commerce NOAA/National Weather Service, 1989: Cooperative station observations. National Weather Service Observing Handbook No. 2, 83 pp.

U.S. Department of Commerce Weather Bureau, 1952: Instructions for climatological observers. 10th ed. Circular B, 60 pp. 